\title{
Self-care management strategies used by Black women who self-report consistent adherence to antihypertensive medication
}

This article was published in the following Dove Press journal:

Patient Preference and Adherence

16 August 2017

Number of times this article has been viewed

\author{
Willie M Abel' \\ Jessica $S$ Joyner ${ }^{2}$ \\ Judith B Cornelius' \\ Danice B Greer ${ }^{3}$ \\ 'School of Nursing, The University \\ of North Carolina at Charlotte, \\ Charlotte, NC, USA; ${ }^{2}$ Internal \\ Medicine, Novant Health First \\ Charlotte Physicians, Matthews, \\ NC, USA; ${ }^{3}$ School of Nursing, \\ The University of Texas at Tyler, Tyler, \\ TX, USA
}

Background: Black women in the USA have the highest prevalence rate of hypertension (HTN) contributing to a higher risk of organ damage and death. Research has focused primarily on poorly controlled HTN, negative belief systems, and nonadherence factors that hinder blood pressure control. No known research studies underscore predominantly Black women who report consistent adherence to their antihypertensive medication-taking. The purpose of this study was to describe self-care management strategies used by Black women who self-report consistent adherence to their antihypertensive medication and to determine the existence of further participation in lifestyle modifications, such as eating a healthy diet and increasing physical activity.

Methods: Using a qualitative descriptive design, four focus groups with a total of 20 Black women aged 25-71 years were audio-taped. Transcripts were analyzed using qualitative content analysis. Participants were included in the study if they scored perfect adherence on the medication subscale of the Hill-Bone Compliance to High Blood Pressure Therapy Scale.

Results: Medication adherence was predicated on three themes: HTN experience, involvement with treatment regimen, and a strong motivated mentality. Black women would benefit from treatment approaches that are sensitive to 1) diverse emotional responses, knowledge levels, and life experiences; 2) two-way communication and trusting, collaborative relationships with active involvement in the treatment regimen; 3) lifestyle modifications that focus on health benefits and individual preferences; and 4) spiritual/religious influences on adherence.

Conclusion: The use of self-care management strategies to enhance antihypertensive medication adherence is key to adequate blood pressure control and the reduction of cardiovascular events. This study provides preliminary insight for future research to develop interventions to aid those Black women who struggle with medication adherence and are disproportionately impacted by HTN.

Keywords: hypertension, medication adherence, self-care management, qualitative focus groups, black women, healthy adherer effect

\section{Background}

Black (used synonymously with African American) women have the highest prevalence of hypertension (HTN) (46.1\%) in the USA, whereas lower rates exist among men (Black 44.9\%, White 32.9\%, and Hispanic 29.6\%) and other women (White $30.1 \%$ and Hispanic 29.9\%). ${ }^{1}$ Because HTN is known as "the silent killer", it often has no warning signs or symptoms, leaving an individual to believe he or she is healthy. ${ }^{2}$ Thus, the asymptomatic nature of HTN is especially dangerous for Blacks because HTN develops early in life with a predisposition to dementia, ${ }^{3,4}$ stroke, heart disease, kidney damage,
Correspondence: Willie M Abel The University of North Carolina at Charlotte, 920I University City Blvd., \#444F CHHS Bldg, Charlotte, NC 28223, USA

Tel +l 7046877949

Email wmabel@uncc.edu 
and even death. ${ }^{1}$ Unfortunately for some, the manifestation of complications associated with HTN might be the first indication of an elevated blood pressure (BP). Equally dangerous, HTN is a major risk factor for cardiovascular disease which is the primary cause of death for women in the USA, with a substantially higher death rate among Black women., Although statistics have shown that Blacks are more aware of their HTN than are other racial/ethnic groups, ${ }^{7}$ they are more likely to have poorly controlled BP. ${ }^{1}$

Aims to reduce HTN can be achieved by modifying risk factors through self-care management behaviors that affect cardiovascular disease such as diet and physical activity ${ }^{8}$ along with antihypertensive drug therapy., ${ }^{9,10}$ However, the reasons Blacks have not readily participated in risk reduction behaviors to manage and prevent HTN are not well understood and are frequently attributed to multiple varied causal factors ${ }^{11}$ ranging from culture ${ }^{12,13}$ to socioeconomic circumstances, psychological and environmental factors, and demographic issues related to healthcare delivery. ${ }^{14-16}$ The most perplexing factor is nonadherence to antihypertensive medications that have proven efficacy in lowering BP. ${ }^{12,17-19}$

HTN research on Blacks has focused primarily on poorly controlled HTN, ${ }^{20}$ negative belief systems, ${ }^{15}$ and medication nonadherence that impedes BP control. ${ }^{21,22}$ In a systematic review on qualitative studies from different racial/ethnic groups in countries around the world, ${ }^{23}$ researchers found similar HTN symptoms and factors that contribute to medication nonadherence. Study participants not only had a knowledge deficit of HTN, but held alternate explanations for their HTN and many purposely chose not to take antihypertensive medication. Also, factors such as racism and economic hardships were distinct to minority ethnic groups. However, lack of trust in White physicians was peculiar to Blacks in the USA. Ever since their slavery, Blacks are confronted with continued segregated communities, high poverty rates, and unequal medical treatment, which places them in a unique position to view healthcare with skepticism, that differs from all other racial/ethnic groups. ${ }^{24-26}$

Currently, the high prevalence of HTN and poor BP control is evidence that current interventions are not working efficiently for Blacks, especially for Black women. Medication adherence research has been conducted in samples of Black men and women ${ }^{22,27-31}$ along with men and women of other racial/ethnic groups. ${ }^{32-35}$ However, there is little research on medication adherence in samples containing only Black women with HTN. ${ }^{21,36-38}$ No known research exists that underscores predominantly Black women who report the selfcare management behavior of consistent adherence to their antihypertensive medication-taking. To capture this aspect of consistent medication-taking, adherence to the treatment regimen from the participant's viewpoint is important for tailoring nursing interventions that could prove effective in Black female populations and fill this gap in the literature.

Medication adherence refers to patients continuing to take their medication as prescribed. ${ }^{39}$ It is estimated that $50 \%-80 \%$ of those diagnosed with HTN do not follow the prescribed medication regimen, resulting in lack of therapeutic effect. ${ }^{40}$ Adherence is an individual behavior ${ }^{40}$ and individuals who are intrinsically motivated to adhere to one aspect of their prescribed treatment demonstrate a freedom of choice in determining their own health status. ${ }^{41}$ This type of motivation is similar to the healthy adherer effect, ${ }^{39}$ which refers to those who are adherent in one aspect of the treatment regimen such as medication-taking are more likely to be adherent in other healthy behaviors. Consistently participating in one aspect of HTN self-care management might eventually lead to other health-promoting lifestyle changes related to BP control. Hence, the purpose of this study was to, 1) describe self-care management strategies used by Black women who self-report consistent adherence to their antihypertensive medication, and 2) determine the existence of further participation in lifestyle modifications such as eating a healthy diet and increasing physical activity.

\section{Methods \\ Study design}

In this study, we used a qualitative descriptive design because there is a paucity of research in the area of self-care management strategies used by Black women who report consistent adherence to antihypertensive medication-taking. Qualitative descriptive design allows a straightforward description of study participant experiences in their own language without the interpretation of existing theories. ${ }^{42,43}$ Used to present an accurate summary of events from participants, the qualitative descriptive approach closely reflects what others would observe as valid. ${ }^{44}$ Focus groups were used to obtain data concerning the experiences and perspectives of Black women who reported consistent adherence to antihypertensive medication-taking. Moreover, to elicit responses from ethnically homogeneous participants regarding ethnic influences on healthcare, the focus group methodology has been found to be more effective. ${ }^{45}$

\section{Participants and procedure}

A purposeful sample of Black women who reported consistent adherence to their antihypertensive medication 
regimen were recruited to participate in this study from the southeastern region of the USA through word of mouth and flyers posted on Facebook and at local churches. Facebook is an innovative and inexpensive method for recruiting research participants ${ }^{46,47}$ and in our study it enabled us to reach a younger population of Black women with HTN. Also, Black churches are known to have a high proportion of Black females. The flyer contained contact information for the principal investigator (PI) and those who called were screened for eligibility through a telephone interview.

The inclusion criteria included: 1) Black women aged 21 years and over, 2) a prescription of one or more antihypertensive medications, 3) English speaking, and 4) consistent adherence to medication-taking as defined by a perfect score on the medication subscale of the Hill-Bone Compliance to High Blood Pressure Therapy Scale (CHBPTS). Scores on the medication subscale range from a minimum score of 9 to a maximum score of 36 , with the score of 9 reflecting perfect medication adherence and higher scores reflecting nonadherence. The Hill-Bone CHBPTS was originally tested and validated using Black populations with $\mathrm{HTN}^{48}$ and has yielded better performance for Black than non-Black populations. Included in the Hill-Bone CHBPTS is the four-item Medication Adherence Scale developed by Morisky et al. ${ }^{49,50}$ The exclusion criteria included: 1) self-report of medical or mental illness that interfered with daily function, 2) current pregnancy, or 3) participation in another research study. Of the 35 women screened for eligibility, 20 met the criteria including a perfect score on the medication subscale of the Hill-Bone CHBPTS during the telephone interview and were invited to participate in the study.

\section{Data collection}

Prior to data collection, the study was approved by the Institutional Review Board at The University of North Carolina at Charlotte. After being informed of the data collection process with a digital voice recorder, each participant provided written informed consent for the study prior to participation. All data were collected during four focus groups held at a church fellowship hall. For each of the focus groups, the PI served as a moderator with one or two female research assistants (RAs). Both of the RAs were registered nurses with master's degree preparation and trained by the PI to serve as observers and note takers during the focus groups.

To guide the focus groups, the PI used semistructured, open-ended questions (Table 1) developed from the literature and framed around the tenets of Orem's Self-Care Deficit Theory major assumptions that people are distinct individuals who should be self-reliant, responsible for their own care, and possess knowledge to identify potential health problems and make needed judgments for self-care. ${ }^{51}$ The focus groups lasted an average of 80 minutes. At the conclusion of the groups, each participant was given a \$20 Wal-Mart gift card and HTN education material from the Preventive Cardiovascular Nurses Association.

\section{Data analysis}

Data were analyzed using qualitative content analysis, ${ }^{42,44,52}$ along with the methods for analyzing focus groups as described by Krueger and Casey. ${ }^{53}$ At the end of each group, member checking was completed to verify the main topics by listing them on a flipchart with participants clarifying and correcting data. All changes, additions, or deletions to previous information were recorded. Following each focus group, the PI and RA(s) conducted a debriefing to discuss factors that could impact analysis, such as dominant or passive participants and things that worked well versus things that did not work well, and suggestions for improvement.

The four focus groups were transcribed verbatim by an independent service and the transcribed files were reviewed with the digital recording by the PI and RA for accuracy. All transcripts were de-identified and then organized with ATLAS.ti software (Version 7.5.10) and augmented with field notes, and discussions from debriefings. Data analysis began after the first focus group and data were repeatedly read and coded by the PI looking for emerging themes using the ATLAS.ti software. After the third interview, data saturation was apparent with no new themes emerging from the data. A fourth focus group was held to ensure that no new information was provided because the second group had only two participants, whereas all other groups had six. Similar codes were grouped together as subthemes and condensed into themes. All subthemes and themes were discussed with two PhD-prepared researchers, experienced in qualitative research, and refined to ensure a thorough and accurate analysis of data. Revisions continued until a consensus was achieved with all researchers.

\section{Results \\ Sample}

Twenty Black women, aged 25-71 years, participated in four focus groups. Three such groups consisted of six participants and one group had two participants. Almost half were married. All participants completed high school or its equivalent. About one-third had 4-year college degrees and one-quarter completed graduate school. Income ranged from $<$ US\$10,000 
Table I Semistructured focus group question examples

\begin{tabular}{|c|c|}
\hline Primary questions and probes & Themes and subthemes \\
\hline $\begin{array}{l}\text { How would you describe your experience with HTN? } \\
\text { - How did you feel when you first found out you had high blood pressure (HBP)? } \\
\text { - What symptoms were you experiencing at that time? } \\
\text { - What concerns you or scares you most about having HBP? } \\
\text { - What changes have you experienced in your normal daily activities that are related to your having HBP? } \\
\text { - Tell me about some of the information you received from your healthcare provider and pharmacist. } \\
\text { - Do you think you got all the information you need to manage your blood pressure (BP) and keep it } \\
\text { controlled? }\end{array}$ & $\begin{array}{l}\text { HTN Experience } \\
\text { - Emotional responses to diagnosis } \\
\text { - Consequences of nonadherence } \\
\text { - Knowledge associated with HTN }\end{array}$ \\
\hline $\begin{array}{l}\text { How has your consistent medication adherence influenced your involvement with HTN treatments } \\
\text { prescribed by your healthcare provider and your relationship with your healthcare provider? } \\
\text { - What do you do to remember to take your BP meds each day? } \\
\text { - How do you monitor your BP to make sure it is within the normal range? } \\
\text { - What are some things that make it easy for you to take your medications every day or follow the BP } \\
\text { - Wreatment plan prescribed by your healthcare provider? } \\
\text { - What are some things that make it difficult for you to take your medications every day or follow the } \\
\text { - Is losing weight a problem for you? What is your personal plan to decrease your weight? } \\
\text { - What types of physical activity do you currently do with the intention of getting health benefits or } \\
\text { getting physically fit? } \\
\text { - What types of soul foods do you currently eat? } \\
\text { - Tour physical activity or change your eating habits? } \\
\text { - Since being diagnosed with HBP, tell me about some home remedies you have used. } \\
\text { - Tell me about any changes you have made in the way you take your HBP medications that is different } \\
\text { from the way your healthcare provider told you to take your HBP medications. } \\
\text { - What do you do if you disagree with the HBP medications or HBP treatment plan that your healthcare } \\
\text { provider has prescribed for you? }\end{array}$ & $\begin{array}{l}\text { Involvement with Treatment Regimen } \\
\text { - Medication routine } \\
\text { - BP monitoring } \\
\text { - Taking BP medications as prescribed } \\
\text { - Lifestyle changes } \\
\text { - Trusting, collaborative relationship } \\
\text { with healthcare provider }\end{array}$ \\
\hline $\begin{array}{l}\text { What is important to your success with medication adherence? } \\
\text { - Does Black culture or your circle of family and friends influence your ability to manage your HBP? } \\
\text { - If you could name one thing that drives your BP up, what would that be? How do you deal with it? } \\
\text { - During your journey with HBP, name one thing that has contributed most to your success in } \\
\text { controlling your BP? } \\
\text { - What or who motivates or influences you to take your HBP medication and do what you need to do } \\
\text { to control your BP. }\end{array}$ & $\begin{array}{l}\text { Strong motivated mentality } \\
\text { - No use of home remedies for HTN } \\
\text { - Medication adherence not } \\
\text { influenced by culture } \\
\text { - Dealing with stress } \\
\text { - Living a quality-life free of HTN } \\
\text { complications } \\
\text { - Strong spiritual/religious beliefs }\end{array}$ \\
\hline
\end{tabular}

Abbreviation: HTN, hypertension.

to $>$ US\$100,000/year. Of the 20 study participants, eight were currently employed or retired from various positions in the healthcare industry. An HTN diagnosis of 10 years or more was reported by more than half of the participants. One-quarter of the participants smoked cigarettes, less than one-third drank alcohol, and one-fifth stated no engagement in physical activity. All participants reported some type of health coverage either through insurance and Medicaid/Medicare or through free clinics. All participants believed in God, and the majority was associated with a religious denomination and attended church services at least once per week (Table 2).

The three themes identified from the data were HTN experience, involvement with treatment regimen, and a strong motivated mentality. The study participants' HTN experiences and a strong motivated mentality helped them maintain consistent involvement with the treatment regimen. Using the main themes as headings, the focus group results are presented below.

\section{Hypertension experience}

Each study participant's experience with HTN differed. When initially diagnosed with HTN, participants expressed emotional responses that ranged from shock, disbelief, denial, fear, depression, and even fatalism. One participant was diagnosed with HTN while in her teens and she stated, “... at 15, I was young. And I thought that God messed up with me, and gave me high blood pressure, and I felt like, depressed. I was really, really upset." Another stated, "I was young. And the first thing I asked, how long do I have to take the medicine? And the doctor asked me how long did I want 
Table 2 Sample characteristics and demographics $(\mathrm{N}=20)$

\begin{tabular}{|c|c|}
\hline Characteristics & $\begin{array}{l}\mathbf{N}(\%) \text { or Mean }( \pm S D) \\
\text { (Range) }\end{array}$ \\
\hline Age (years) & $54.7( \pm \mid 3.09)(25-7 \mid)$ \\
\hline \multicolumn{2}{|l|}{ Marital status } \\
\hline Single (never married) & $4(20)$ \\
\hline Married & $9(45)$ \\
\hline Separated/divorced & $7(35)$ \\
\hline \multicolumn{2}{|l|}{ Employment status } \\
\hline Employed & II (55) \\
\hline Unemployed/disabled & $3(15)$ \\
\hline Retired & $6(30)$ \\
\hline \multicolumn{2}{|l|}{ Education } \\
\hline High school graduate/GED or equivalent & $3(15)$ \\
\hline Some community college & $4(20)$ \\
\hline Graduated community college & $2(10)$ \\
\hline Graduated 4-year college & $6(30)$ \\
\hline Completed graduate school & $5(25)$ \\
\hline \multicolumn{2}{|l|}{ Income } \\
\hline$<\$ 19,999$ & $4(20)$ \\
\hline$\$ 20,000$ to $\$ 34,999$ & $4(20)$ \\
\hline$\$ 35,000$ to $\$ 54,999$ & $2(10)$ \\
\hline$\$ 55,000$ to $\$ 74,999$ & $6(30)$ \\
\hline$\$ 75,000$ to $>\$ 100,000$ & $4(20)$ \\
\hline \multicolumn{2}{|c|}{ Years diagnosed with hypertension, years } \\
\hline$<10$ & $7(35)$ \\
\hline $10-20$ & $10(50)$ \\
\hline $30-38$ & $3(15)$ \\
\hline \multicolumn{2}{|l|}{ Current cigarette smoker } \\
\hline No & $15(75)$ \\
\hline Yes & $5(25)$ \\
\hline \multicolumn{2}{|l|}{ Currently drink alcohol } \\
\hline No & $14(70)$ \\
\hline Yes & $6(30)$ \\
\hline \multicolumn{2}{|l|}{ Engage in physical activity } \\
\hline No & $4(20)$ \\
\hline I-3 days per week & $9(45)$ \\
\hline 4-7 days per week & $7(35)$ \\
\hline \multicolumn{2}{|l|}{ Health coverage } \\
\hline Insurance & $14(70)$ \\
\hline Medicaid/medicare & $5(25)$ \\
\hline Free clinic & I (5) \\
\hline Belief in God & $20(100)$ \\
\hline \multicolumn{2}{|l|}{ Religious denomination } \\
\hline Baptist & $13(65)$ \\
\hline Other denomination & $5(25)$ \\
\hline None & $2(10)$ \\
\hline \multicolumn{2}{|l|}{ Church attendance } \\
\hline More than once a week & $7(35)$ \\
\hline Every week & $10(50)$ \\
\hline One to two times per month & $3(15)$ \\
\hline
\end{tabular}

Abbreviation: GED, general educational development or high school equivalency diploma.

to live?" For those with a family history, HTN was deemed inevitable. One participant stated,

I really didn't have any feelings of negativity or anything when I found out that I had high blood pressure, because it had ran in my family. So it just seemed like it was something that was going to happen.
Another participant was fearful that antihypertensive medications had long-term side-effects and stated

... usually, when you take medicine, it's helping one thing and it's hurting something else. It's keeping the blood pressure down, but is it causing something else to malfunction....

Knowing that a heart attack or stroke was a consequence of not taking antihypertensive medication was a major motivating factor for adherence to the medication treatment regimen. Participants were frightened at the thought of having a stroke with paralysis, resulting in the inability to engage in self-care. One participant stated,

Not being able to take care of yourself if you have a stroke, to be in a wheelchair, or not to be able to communicate with someone to tell them how you feel, or in my case, I worry about, will I be paralyzed? Can I use my arms? I mean it's always there, and that's what makes you go ahead and take those pills. They said this is supposed to help you ... What can happen if you don't take it? You could be seriously ill. So you error on the side of I'd rather be healthy. This going to keep me healthy? I'm going to take it.

Others were concerned about the asymptomatic nature of HTN that increases their risk for adverse events. The group concluded that they wanted to take their medication to maintain their health.

Knowledge about HTN and antihypertensive medications was important to participants. Participants felt they got most of the information they needed from their healthcare provider, along with the prescription drug information sheet from the pharmacist. One participant shared, "I go online to read more about that medication, cause that wasn't enough information for me...." The group wanted to empower itself by taking advantage of every opportunity to be knowledgeable about HTN and antihypertensive medications.

Several study participants who worked in healthcare were not given HTN information because their provider assumed they were knowledgeable on the topic. Members from the group felt this was not acceptable and thought healthcare professionals should be treated as any other patient. A member reflected on the need for healthcare professionals with HTN to hear relevant information from a patient's perspective, “... It doesn't matter what I know. It's what I need to hear from you." Study participants believed that their HTN diagnosis was a shared responsibility between them and their healthcare provider. Participants agreed that the healthcare provider needed to provide adequate information and then “... it's up to me." Group members felt a need to work with 
healthcare providers and control what they could in their lives to help maintain their BP at an acceptable level.

Participants in this study were not likely to receive information from family and friends regarding their BP treatment, especially with regard to using home remedies instead of their prescribed medication. Concerning advice and remedies from others, a participant stated, "Myths will get you killed every time." They realized the danger in taking advice from those who did not have the credentials to practice medicine. Participants concurred that they needed to stick to the medication prescribed by their healthcare provider.

\section{Involvement with treatment regimen}

All study participants were actively involved in their treatment regimen. Participants felt that developing a medication routine was vital to adhering to their medication-taking schedule prescribed by their healthcare provider. All participants had a routine for taking their BP medication at the same time every day, whether it was before breakfast or after getting dressed. One participant stated,

When I do my devotion every morning, I get my bottle and take my pill out, and set it on my dresser, so when I'm done with my devotion, I get a glass of water, and take it then.

A few even kept a supply of pills in their purse as a safety net, just in case they forgot to take their medication as scheduled.

Being able to monitor their BP at home was another factor in the treatment regimen. The majority of participants were knowledgeable about their personal BP range, owned a BP device, measured their BP once per day or several times per week, and kept a log to report their BP numbers to the healthcare provider by email or during office appointments. Others relied on getting BP readings periodically from an automated BP machine at a local drug store or during scheduled appointments with their healthcare provider.

Taking antihypertensive medications as prescribed by the healthcare provider was easy for the study participants. The main incentive was the desire to be free from other sicknesses and diseases while growing older. A participant said, “... You make the choice to either do what you're supposed to do or not do it, and suffer the consequence. It's a lifestyle choice." Also, participants wanted to live healthy lives so they could see their children and grandchildren grow up. Barriers that could make medication adherence difficult were identified and these included high medication costs, waiting in long queues at Walmart, having a 30-day supply instead of a 90-day supply because their health insurance would not pay for 90-day supplies, and just getting tired of taking medication all the time. All participants agreed that medication-taking is not dependent on how they felt about the process, but that it is a lifelong commitment that accompanies living with HTN. One participant echoed the thoughts of the group by saying,

... Oh, God, I'm awful tired of taking this stuff. I don't wanna take it anymore. Even though I know I gotta take it, I feel like, I'm tired of taking it, but I'll take it ...

Although weight data were not obtained on study participants, the majority were observed to be overweight or obese. Participants voiced that they had been trying to lose weight by cutting back on food with some success. Healthy food choices were mentioned by participants, who stated they had made dietary modifications such as eating food without salt, giving up fried foods, not consuming pork anymore and not cooking with fat products. One participant described how she ate in moderation by saying,

I didn't give up any foods. I went to the salad plate. I've just changed the size of my plate. But I still eat everything, and it's on that little plate, and it's not running over, and it's not stacked this high. But I get like a spoon of this, a spoon of that, and I'm satisfied, because in the process,

I drink my water.

Eighty percent of the participants found value in physical activity, whereas others either had future plans for it, were less motivated, or had health issues. Activities included walking, participating in various exercise classes at the YMCA, dance movements to music when doing housework, and repetitive leg and arm movements while watching television. One participant stated, “... I noticed now when I do my walking, I sleep better." Things that hindered physical activity for participants were dogs let loose in their neighborhood, cold weather, allergies, joint pain, and a dislike of exercise. One participant thought that having a treadmill at home would increase her physical activity because she could use it any time.

The importance of a trusting relationship with the healthcare provider was discussed. Caring, compassion, unhurried approach, and frank dialogue were terms used to describe providers who were trusted. Participants agreed that trust in their provider influenced their willingness to take their medication as prescribed. Providers who were honest and dealt with issues directly helped participants maintain adherence to medications. One participant said, "I like my 
doctor. She's very frank. She doesn't bite her tongue. She lets me have it, whatever it is." Participants wanted providers who took the time to sit down and talk with them through two-way communication. Those participants who reported the best collaborative, trusting relationships had Black female providers. Being able to trust and partner with providers on the HTN treatment regimen was important to participants and they adamantly agreed they would search for a new provider if communication and/or trust were an issue.

\section{Strong motivated mentality}

Although all participants denied the use of home remedies, the remedy cited the most for high BP was vinegar. Several participants reported using vinegar in the past to reduce their BP, but they admitted the result was short term. When first diagnosed with HTN, a few participants admitted to not following their prescribed medication schedule and would miss medication dosages or change their schedule from twice a day to once a day, resulting in poor BP control. All study participants agreed that medication adherence was a high priority. The consensus of the group was reflected in one participant's statement,

My thing is, why go to the doctor if you're not gonna do anything? Why go? You know, why waste your time going to hear that if you're not gonna do it?

The medication adherence of study participants was not influenced by Black culture or by their circle of family and friends. One participant said,

I'm not going to be doing what my mama says; take no tablespoon of vinegar. I'm just going to take my medicine. So then, they (family and friends) don't have an effect on me.

Overall, family and friends were viewed as a good influence in helping to keep participants on track. A participant said,

If I'm eating something that I know I'm not supposed to, they'll get on me because a couple of my sisters and brothers have high blood pressure, so we know what each other's going through ...

Study participants identified stress as the primary issue that increased their BP. Also, participants thought anger was closely related to stress. Methods of dealing with stress and anger were discussed, such as walking away from their source, identifying the stressor, and working through it. One participant stated,
If I feel like I'm stressed, I have to get away. I have to go in my own closet and close the door, talk to the Lord, and let him have it. Let him take care of everything. And then I come back stress-free. Don't have to worry about it.

Participants agreed that stress and anger could be destructive, both physically and mentally. One participant suggested that the group should use the theme song, "Let it go," from the computer-animated movie, "Frozen." Participants also felt they had a higher degree of stress that differs from that of other racial/ethnic groups, especially White women, who they believed did not have to work as hard because they had more opportunities than Black women. All were determined they would not be controlled by stress nor would they let other people supplant the medical instruction received from healthcare providers. One participant said, “... if you do not have a license, you cannot tell me anything ... show me documentation on this, because this is my life."

Living a good quality of life without the adverse effects of HTN influenced the desire of study participants to consistently take their antihypertensive medications. Participants were self-motivated to take their medication because they did not want to experience the consequences of nonadherence. Participants stated they were motivated to take their medication because of "My children" or "My family" or "because I want to live". Four participants were nurses and the patients they cared for motivated them to adhere to their medication-taking regimen because they wanted to be good role models and lead by example. The hope of becoming medication-free was a powerful influence to not only take the antihypertensive medication consistently, but also to engage in making lifestyle changes. A participant stated,

My biggest motivator is to get all this medicine out of my home. I just wanna stop taking it. And if I can control it, you know, doing all the proper things, then that's what I wanna do.

Making a choice every day to adhere to medication treatment was a commitment influenced by the participant's strong spiritual/religious beliefs. Participants acknowledged,

... we can't do anything without acknowledging the fact that there's a God that's guiding us ... God wants us to take care of his temple (physical body).

Taking care of God's temple meant participants had to engage in self-care. Study participants agreed, "We have to 
learn to take care of ourselves. Not just everybody else, but ourselves." Participants had a steadfast belief that the God they served was able to help them through any situation they might encounter. Although HTN had disrupted their lives, they were inspired by their God and this strengthened their mentality and gave them a sense of peace concerning life's obstacles. One participant asserted,

Learn to voice your concerns with your healthcare provider.

And I mean be specific. And don't give up if they don't give you the information you need ...

\section{Discussion}

When initially diagnosed with HTN, study participants were confronted with the emotional challenge of living with a chronic condition. For some, the issues were temporary and for others, it took years to overcome, resulting in some being adherent to antihypertensive medication-taking at the onset of their diagnosis and others being adherent over time. This study captures a time point in the lives of Black women where they had learned to personalize medication adherence as a part of themselves while realizing it was not about whether they liked to take medication, rather, whether they wanted to live a quality life without the adverse effects of HTN. The HTN experience and a motivated mind-set contributed to a resolve to adhere to antihypertensive medication-taking.

The purpose of this study was to describe self-care management strategies used by Black women who self-reported consistent adherence to their antihypertensive medicationtaking and determine the existence of further participation in lifestyle modifications. The self-care management behavior of medication-taking led to other health-promoting lifestyle changes such as healthier diets and physical activity in the majority of study participants. Focusing on the benefits of healthy diets and physical activity inclusive of spiritual/ religious beliefs might be an effective method of increasing adherence. Also, it is important to assess dietary and physical activity preferences that individuals will enjoy and potentially accomplish more often. Three themes emerged from the data: HTN experience, involvement with treatment regimen, and a strong motivated mentality.

In the first theme, participants described their emotions, inspirations, and intellectual needs. The fear of living with a physical impairment from a stroke or heart disease was a major concern for participants and served as a key motivating factor for medication adherence self-care behaviors. Thus, addressing the patient's perception of the adverse effects of HTN could potentially contribute to medication adherence. ${ }^{40}$
The current study results were similar to those of other studies, in that the family served as a motivation for adherence to the medication treatment regimen. ${ }^{21}$ The majority of participants $(65 \%)$ had completed some form of higher education and $40 \%$ of them had experience working in the healthcare industry. Low educational levels are frequently cited as a reason for medication nonadherence, ${ }^{39}$ whereas higher education is associated with an increased likelihood of medication adherence. ${ }^{54}$ Even though knowledge in itself is not enough to ensure adherence, it is necessary for adherence and self-care behaviors to occur. ${ }^{55}$ Likewise, participants in the current study seemed adept at conversing with their healthcare providers and believed they received adequate educational information to manage their HTN. Although women in this study stated they had good relationships with their healthcare providers, it is uncertain if docile relationships exist among women who are nonadherent to medication-taking.

The second theme, involvement with treatment regimen, referred to the practices that participants engaged in to maintain self-care management strategies for medication adherence and BP control. All women in the study described self-care management strategies that they used to consistently adhere to their antihypertensive medication-taking, such as an established medication-taking routine and pill boxes to organize their medications weekly. Also, personal BP monitoring allowed participants to keep track of their BP numbers and share the results with their healthcare provider, giving them an opportunity to actively participate in their treatment regimen. In one study, ${ }^{56} \mathrm{BP}$ self-monitoring was used to actively involve patients in their care and to assist them in taking ownership of their BP. Home BP monitoring is cited as being beneficial in terms of reduced BP, improved BP control, and adherence to antihypertensive medication. ${ }^{57,58}$

Participants in this study reported consistent medicationtaking and the majority reported active involvement with lifestyle modifications such as healthy diet and increased physical activity. As a result of dietary practices and inactivity, Black women in the USA have the highest prevalence of overweight and obesity when compared with other racial/ethnic groups. ${ }^{1}$ In the current study, although participants were observed to be either overweight or obese, $90 \%$ reported changes to their diets that included reducing salt, pork, and fried foods, while increasing fresh fruits and vegetables. Participants also reported different ways to cook typical "Soul Food" to maintain healthy eating habits. Eating a heart-healthy diet such as the Dietary Approaches to Stop Hypertension (DASH) diet helps to lower BP and 
reduce the risk of cardiovascular disease. ${ }^{59}$ However, the DASH diet does not take into account cultural food preference and environmental barriers. ${ }^{60,61}$ Black participants in the trial related to Exercise and Nutritional Interventions for Cardiovascular Health were less adherent to the DASH diet, suggesting cultural influences on food preference and preparation, as well as social context restraints that include the high cost of healthy foods and reduced availability of healthy foods in poorer neighborhoods. Instituting dietary strategies that are culturally relevant might contribute to DASH diet adherence. ${ }^{62}$

When discussing attempts to lose weight and increase physical activity, $80 \%$ of participants stated that they consistently engaged in physical activity. In other studies, barriers to physical activity included fatigue, lack of motivation, cost of exercise facilities, caregiving responsibilities, ruined hair-dos, lack of social support, underestimation of body size, and safety and environmental concerns. ${ }^{63-65}$ To increase physical activity in Black women, the incorporation of spiritual/religious beliefs with a focus on chronic disease prevention and health benefits rather than weight loss and body mass index has been effective. In addition, consideration should be given to the types of physical activities Black women prefer that tend to differ from those of White women, and might include basketball and jump rope instead of hiking and ice skating. ${ }^{63}$ Eating a healthy diet and participating in physical activities were operational to almost the same extent as medication adherence among participants in this study.

Among Blacks with HTN, trust in the healthcare provider is associated with medication adherence. ${ }^{36,66} \mathrm{In}$ contrast, other studies reported no relationship between trust and medication adherence ${ }^{67}$ nor trust and BP control. ${ }^{68}$ In the current study, a trusting relationship with a healthcare provider, especially a Black female provider, influenced medication adherence. However, another study found that the race of the healthcare provider was not a significant factor in medication adherence if the quality of the communication was collaborative. ${ }^{69}$ Forty percent of the participants in this study had experience working in healthcare and $65 \%$ had completed community college or higher, which could have influenced their knowledge and expectations of quality healthcare services. Likewise, when healthcare providers attend to patients who are adherent, cooperative, and knowledgeable, it might also influence the quality of interactions and services provided. Thus, the establishment of trusting relationships may be contingent on a number of patient and provider factors.

The final theme, a strong motivated mentality, was described as the influence of self-motivation and spiritual/ religious beliefs on self-care management strategies for medication adherence. The firm motivation of participants superseded their circle of family and friends' advice for the use of home remedies. As the most religiously devout group of all racial/ethnic groups in the USA,${ }^{70}$ Blacks and especially Black women ${ }^{71}$ express higher levels of spiritual/ religious beliefs. Participants in this study felt the only way they could adhere to medication-taking was with the help of God's guidance. Similarly, in a study conducted by Lewis, ${ }^{37}$ older African American women with HTN used their spiritual beliefs to help them adhere to antihypertensive medications. However, participants in an African country relied on their spirituality for divine healing and were nonadherent to taking antihypertensive medications. Also, stressed patients were more likely to be nonadherent to antihypertensive medicationtaking. ${ }^{72}$ In contrast, Koenig ${ }^{73}$ found that spiritual/religious beliefs and practices tend to have a positive influence on mental/physical health and health behaviors.

This was the first known qualitative study to explore selfcare management strategies used by Black women with HTN who reported consistent medication adherence. The focus groups provided insight into self-care practices, inclusive of the emotional and intellectual HTN experiences, multiple levels of involvement with the treatment regimen, and the incorporation of motivation and spiritual/religious beliefs. Although self-care management strategies identified in this study are not entirely new, there is evidence in the literature that these strategies are not routinely addressed and/or prescribed for hypertensive patients with consistent follow-up by healthcare providers. Poor execution of evidence-based HTN guidelines, insufficient attention to health education, and clinical inertia among healthcare providers contribute to poor BP control ${ }^{74,75}$ and create significant barriers to HTN management.

Because of the historical legacy and the diverse experiences of Blacks with the healthcare system, different treatment approaches might be needed. Rather than culturally specific methods with intervention strategies that might not fit the majority, a holistic (mind, body, and spirit) approach that is individualistic and incorporating the concerns and perspectives of the patient ${ }^{23}$ is needed to obtain optimal health outcomes. Tailoring interventions to the unique characteristic of each patient with HTN and their specific treatment regimen is an important point that is often overlooked by healthcare providers. Findings from this study suggest the need for healthcare providers to engage in two-way communication and individualize the treatment approach with multifaceted interventions that build knowledge, trust, 
collaboration, active participation, and the incorporation of spiritual/religious beliefs. These interventions are simplistic and involve no cost, except time, and a humane approach that empowers patients to take charge of their health.

\section{Limitations}

There were a number of limitations in this study. Participants were recruited by word of mouth and flyers posted on Facebook and at local churches, and this reflects the self-selection bias of those who agreed to participate in this study. Also, this study was conducted in the Bible belt of the USA, and each participant reported a belief in God and attended church services at least once per month or more often. Therefore, the study results might not be representative of all Black women with HTN or even those in other settings or geographical locations. The sample in this study was highly educated and almost half were married, in comparison with the general population. Also, only Black women were interviewed and their experiences may not reflect those of other racial/ethnic groups. In addition, the use of self-reported medication adherence information was collected with the Hill-Bone Compliance to High Blood Pressure Therapy Scale. Thus, the subjective nature of the scale might not accurately reflect the under-reporting of nonadherent behaviors. Further, BP was not measured and participants did not self-report their BP because the study focused on the strategies that participants used to achieve medication adherence. Despite these limitations, we believe that our findings add to the dearth of literature on successful strategies for antihypertensive medication adherence in Black women.

\section{Implications}

The study has provided important highlights regarding self-care management strategies used by Black women who self-report consistent adherence to their antihypertensive medication. Black women could benefit from treatment approaches that are sensitive to: 1) diverse emotional responses, knowledge levels, and life experiences; 2) twoway communication and trusting, collaborative relationships with active involvement in the treatment regimen; 3) lifestyle modifications that focus on health benefits and individual preferences; and 4) spiritual/religious influences on adherence. The results of this study provide preliminary insight for future research to develop interventions to aid those Black women who struggle with medication adherence and are disproportionately impacted by HTN.

\section{Conclusion}

Almost half of all Black women in the USA are disparately affected by HTN. The use of self-care management strategies to enhance antihypertensive medication adherence is key to adequate BP control and the reduction of cardiovascular events. The thoughts and beliefs expressed by participants in this study provide important insights into the strategies needed to maximize the potential for consistent medication adherence. If success is achieved with medication adherence, it is possible for the healthy adherer effect to be operative whereby those who are adherent in one aspect of their treatment regimen are more likely to be adherent in other behaviors such as healthy diets and increased physical activity. While the findings of this study add to the relatively sparse literature on medication adherence in Black women, more research is needed to support these findings. Currently, a pilot research is planned to use the results from this study to develop several biobehavioral interventions designed to promote self-care management and adherence to the medication treatment regimen among hypertensive Black women. The pilot study will test the feasibility, acceptability, and efficacy of the interventions.

\section{Acknowledgments}

The author(s) disclosed receipt of the following financial support for the research and publication of this article. This study was funded by The University of North Carolina at Charlotte Faculty Research Grant and the publication was funded by the J. Murrey Atkins Library Open Access Article Publication Subvention Fund. The authors thank Yolondra Cochran for assisting with data collection.

\section{Disclosure}

The authors report no conflicts of interest in this work.

\section{References}

1. Mozaffarian D, Benjamin EJ, Go AS, et al; American Heart Association Statistics Committee; Stroke Statistics. Heart disease and stroke statistics-2016 update: a report from the American Heart Association. Circulation. 2016;133(4):e38-e360.

2. Sawicka K, Szczyrek M, Jastrzębska I, Prasal M, Zwolak A, Daniluk J. Hypertension - the silent killer. J Pre-Clin Clin Res. 2011;5(2):43-46.

3. Obisesan TO. Hypertension and cognitive function. Clin Geriatr Med. 2009;25(2):259-288.

4. Elias MF, Goodell AL, Dore GA. Hypertension and cognitive functioning: a perspective in historical context. Hypertension. 2012;60(2):260-268.

5. Centers for Disease Control and Prevention. Leading causes of death in females-2013; 2015. Available from: http://www.cdc.gov/women/lcod/ index.htm. Accessed January 09, 2017.

6. Williams RA. Cardiovascular disease in African American women: a health care disparities issue. J Natl Med Assoc. 2009;101(6):536-540. 
7. Olives C, Myerson R, Mokdad AH, Murray CJL, Lim SS. Prevalence, awareness, treatment, and control of hypertension in United States counties, 2001-2009. PLoS One. 2013;8(4):e60308.

8. World Heart Fedration. Cardiovascular disease risk factors; 2016. Available from: http://www.world-heart-federation.org/cardiovascular-health/ cardiovascular-disease-risk-factors/. Accessed January 11, 2017.

9. Douglas JG, Bakris GL, Epstein M, et al; Hypertension in African Americans Working Group of the International Society on Hypertension in Blacks. Management of high blood pressure in African Americans: consensus statement of the Hypertension in African Americans Working Group of the International Society on Hypertension in Blacks. Arch Intern Med. 2003;163(5):525-541.

10. Flack JM, Sica DA, Bakris G, et al; International Society on Hypertension in Blacks. Management of high blood pressure in Blacks: an update of the international society on hypertension in blacks consensus statement. Hypertension. 2010;56(5):780-800.

11. Fuchs FD. Why do Black Americans have higher prevalence of hypertension?: an enigma still unsolved. Hypertension. 2011;57(3): 379-380.

12. Fongwa MN, Evangelista LS, Doering LV. Adherence to treatment factors in hypertensive African American women. $J$ Cardiovasc Nurs. 2006;21(3):201-207.

13. Abel WM, Crane PB, McCoy T. Predictors of depression in Black women with hypertension. Issues Ment Health Nurs. 2014;35(3):165-174.

14. Webb MS, Gonzalez LO. The burden of hypertension: mental representations of African American women. Issues Ment Health Nurs. 2006; 27(3):249-271.

15. Lukoschek P. African American's beliefs and attitudes regarding hypertension and its treatment: a qualitative study. J Health Care Poor Underserved. 2003;14(4):566-587.

16. Kressin NR, Wang F, Long J, et al. Hypertensive patients' race, health beliefs, process of care, and medication adherence. J Gen Intern Med. 2007;22(6):768-774.

17. Mabotuwana T, Warren J, Kennelly J. A computational framework to identify patients with poor adherence to blood pressure lowering medication. Int J Med Inform. 2009;78(11):745-756.

18. Martins D, Gor D, Teklehaimanot S, Norris K. High blood pressure knowledge in an urban African-American community. Ethn Dis. 2001; 11(1):90-96

19. Chobanian AV, Bakris GL, Black HR, et al. The seventh report of the joint national committee on prevention, detection, evaluation, and treatment of high blood pressure. Bethesda, MD: US Department of Health and Human Services. National Institutes of Health (NIH Publication No 04-5230). 2004.

20. Schoenthaler A, Luerassi L, Teresi JA, et al. A practice-based trial of blood pressure control in African Americans (TLC Clinic): study protocol for a randomized controlled trial. Trials. 2011;12:265.

21. Fongwa MN, Evangelista LS, Hays RD, et al. Adherence treatment factors in hypertensive African American women. Vasc Health Risk Manag. 2008;4(1):157-166.

22. Solomon A, Schoenthaler A, Seixas A, Ogedegbe G, Jean-Louis G, Lai D. Medication routines and adherence among hypertensive African Americans. J Clinl Hypertens. 2015;17(9):668-672.

23. Marshall IJ, Wolfe CD, McKevitt C. Lay perspectives on hypertension and drug adherence: Systematic review of qualitative research. BMJ. 2012;345:e3953

24. Washington HA. Medical Apartheid: The Dark History of Medical Experimentation On Black Americans from Colonial Times to the Present. New York: Anchor Books; 2006.

25. Smedley BD, Stith AY, Nelson AR, eds. Unequal Treatment: Confronting Racial and Ethnic Disparities in Health Care. Washington, DC: The National Academies Press; 2003.

26. Macartney S, Bishaw A, Fontenot K. Poverty Rates for Selected Detailed Race and Hispanic Groups by State and Place: 2007-2011. In: Survey AC, ed. Vol Report Number: ACSBR/11-17: United States Census Bureau; 2013.
27. Cuffee YL, Hargraves JL, Rosal M, et al. Reported racial discrimination, trust in physicians, and medication adherence among inner-city African Americans with hypertension. Am J Public Health. 2013;103(11): e55-e62.

28. Braverman J, Dedier J. Predictors of medication adherence for African American patients diagnosed with hypertension. Ethn Dis. 2009; 19(4):396-400.

29. Ogedegbe G, Chaplin W, Schoenthaler A, et al. A practice-based trial of motivational interviewing and adherence in hypertensive African Americans. Am J Hypertens. 2008;21(10):1137-1143.

30. Schoenthaler A, Ogedegbe G. Patients' perceptions of electronic monitoring devices affect medication adherence in hypertensive African Americans. Ann Pharmacother. 2008;42(5):647-652.

31. Ogedegbe G, Harrison M, Robbins L, Mancuso CA, Allegrante JP. Barriers and facilitators of medication adherence in hypertensive African Americans: a qualitative study. Ethn Dis. 2004;14(1):3-12.

32. Brewer LC, Carson KA, Williams DR, Allen A, Jones CP, Cooper LA. Association of race consciousness with the patient-physician relationship, medication adherence, and blood pressure in urban primary care patients. Am J Hypertens. 2013;26(11):1346-1352.

33. Kim MM, Howard DL, Kaufman JS, Holmes D. Predicting medication use in an elderly hypertensive sample: revisiting the Established Populations for Epidemiologic Studies of the Elderly study. J Natl Med Assoc. 2008;100(12):1386-1393.

34. Ogedegbe G, Schoenthaler A, Fernandez S. Appointment-keeping behavior is not related to medication adherence in hypertensive African Americans. J Gen Intern Med. 2007;22(8):1176-1179.

35. Holt E, Joyce C, Dornelles A, et al. Sex differences in barriers to antihypertensive medication adherence: findings from the Cohort Study of Medication Adherence Among Older Adults (CoSMO). J Am Geriatr Soc. 2013;61(4):558-564.

36. Abel WM, Efird JT. The Association between trust in health care providers and medication adherence among black women with hypertension. Front Public Health. 2013;1:66.

37. Lewis LM. Medication adherence and spiritual perspectives among African American older women with hypertension. A qualitative study. J Gerontol Nurs. 2011;37(6):34-41.

38. Greer DB, Ostwald SK. Improving adherence in African American women with uncontrolled hypertension. J Cardiovasc Nurs. 2015;30(4) 311-318.

39. Ho PM, Bryson CL, Rumsfeld JS. Medication adherence: its importance in cardiovascular outcomes. Circulation. 2009;119(23):3028-3035.

40. Brown MT, Bussell JK. Medication adherence: WHO cares? Mayo Clin Proc. 2011;86(4):304-314.

41. Abel WM, Barksdale DJ. Freedom of choice and adherence to the health regimen for African Americans with hypertension. ANS Adv Nurs Sci. 2012;35(4):E1-E8.

42. Neergaard MA, Olesen F, Andersen RS, Sondergaard J. Qualitative description - the poor cousin of health research? BMC Med Res Methodol. 2009;9:52. Available from: http://bmcmedresmethodol.biomedcentral. com/articles/10.1186/1471-2288-9-52. Accessed January 17, 2017.

43. Sandelowski M. Whatever happened to qualitative description? Res Nurs Health. 2000;23(4):334-340.

44. Sandelowski M. What's in a name? Qualitative description revisited. Res Nurs Health. 2010;33(1):77-84.

45. Greenwood N, Ellmers T, Holley J. The influence of ethnic group composition on focus group discussions. BMC Med Res Methodol. 2014;14:107.

46. Kapp JM, Peters C, Oliver DP. Research recruitment using Facebook advertising: big potential, big challenges. J Cancer Educ. 2013;28(1): 134-137.

47. Valdez RS, Guterbock TM, Thompson MJ, et al. Beyond traditional advertisements: Leveraging Facebook's social structures for research recruitment. J Med Internet Res. 2014;16(10):e243.

48. Kim MT, Hill MN, Bone LR, Levine DM. Development and testing of the hill-bone compliance to high blood pressure therapy scale. Prog Cardiovasc Nurs. 2000;15(3):90-96. 
49. Morisky DE, Green LW, Levine DM. Concurrent and predictive validity of a self reported measure of medication adherence. Med Care. 1986; 24(1):67-74.

50. Hill MN, Bone LR, Kim MT, Miller DJ, Dennison CR, Levine DM. Barriers to hypertension care and control in young urban black men. Am J Hypertens. 1999;12(10 Pt 1):951-958.

51. Orem DE. Nursing: Concepts of Practice. 4th ed. St. Louis, MO: MosbyYear Book Inc; 1991.

52. Sandelowski M. Focus on research methods. Whatever happened to qualitative description? Res Nurs Health. 2000;23:334-340.

53. Krueger RA, Casey MA. Focus Groups: A Practical Guide for Applied Research. 4th ed. Thousand Oaks CA: Sage Publications; 2009.

54. Munger MA, Van Tassell BW, LaFleur J. Medication nonadherence: an unrecognized cardiovascular risk factor. MedGenMed. 2007; 9(3):58.

55. Pascucci MA, Leasure AR, Belknap DC, Kodumthara E. Situational challenges that impact health adherence in vulnerable populations. J Cult Divers. 2010;17(1):4-12.

56. Friedewald VE, Nesbitt SD, Ram VS, Roberts WC. The editor's roundtable: Hypertension in African Americans and other non-Caucasian ethnic groups. Am J Cardiol. 2010;106(10):1466-1472.

57. Margolis KL, Asche SE, Bergdall AR, et al. Effect of home blood pressure telemonitoring and pharmacist management on blood pressure control: the hyperlink cluster randomized trial. JAMA. 2013; 310(1):46-56.

58. Breaux-Shropshire TL, Brown KC, Pryor ER, Maples EH. Prevalence of blood pressure self-monitoring, medication adherence, selfefficacy, stage of change, and blood pressure control among municipal workers with hypertension. Workplace Health Saf. 2012;60(6): 265-271.

59. Appel LJ, Brands MW, Daniels SR, Karanja N, Elmer PJ, Sacks FM; American Heart Association. Dietary approaches to prevent and treat hypertension: a scientific statement from the American Heart Association. Hypertension. 2006;47(2):296-308.

60. Whitt-Glover MC, Hunter JC, Foy CG, et al. Translating the Dietary Approaches to Stop Hypertension (DASH) diet for use in underresourced, urban African American communities, 2010. Prev Chronic Dis. 2013; 10:120088.

61. Bertoni AG, Foy CG, Hunter JC, Quandt SA, Vitolins MZ, WhittGlover MC. A multilevel assessment of barriers to adoption of Dietary Approaches to Stop Hypertension (DASH) among African Americans of low socioeconomic status. J Health Care Poor Underserved. 2011; 22(4):1205-1220.
62. Epstein DE, Sherwood A, Smith PJ, et al. Determinants and consequences of adherence to the DASH diet in African American and white adults with high blood pressure: results from the ENCORE trial. J Acad Nutr Diet. 2012;112(11):1763-1773.

63. Pekmezi D, Marcus B, Meneses K, et al. Developing an intervention to address physical activity barriers for African-American women in the deep south (USA). Womens Health (Lond). 2013;9(3):301-312.

64. Ray R. An intersectional analysis to explaining a lack of physical activity among middle class black women. Sociology Compass. 2014;8(6): 780-791.

65. Joseph RP, Ainsworth BE, Keller C, Dodgson JE. Barriers to physical activity among African American women: an integrative review of the literature. Women Health. 2015;55(6):679-699.

66. Elder K, Ramamonjiarivelo Z, Wiltshire J, et al. Trust, medication adherence, and hypertension control in Southern African American men. Am J Public Health. 2012;102(12):2242-2245.

67. Applegate BW, Ames SC, Mehan DJ Jr, McKnight GT, Jones GN, Brantley PJ. Maximizing medication adherence in low-income hypertensives: a pilot study. J La State Med Soc. 2000;152(7):349-356.

68. Durant RW, McClure LA, Halanych JH, et al. Trust in physicians and blood pressure control in blacks and whites being treated for hypertension in the REGARDS study. Ethn Dis. 2010;20(3):282-289.

69. Schoenthaler A, Chaplin WF, Allengrante JP, et al. Provider communication effects medication adherence in hypertensive African Americans. Patient Educ Couns. 2009;75(2):185-191.

70. Vu, M. A. African-Americans most religiously devout group. 2009, February 2. Available from http://www.christianpost.com/article/20090202/ african-americans-most-religiously-devout-group/index.html. Accessed January 19, 2017.

71. Newport F. Seven in 10 Americans are very or moderately religious. 2012; Available from: http:/www.gallup.com/poll/159050/sevenamericans-moderately-religious.aspx. Accessed January 19, 2017.

72. Kretchy IA, Owusu-Daaku FT, Danquah SA. Mental health in hypertension: assessing symptoms of anxiety, depression and stress on anti-hypertensive medication adherence. Int $J$ Ment Health Syst. 2014;8:25.

73. Koenig HG. Religion, spirituality, and health: the research and clinical implications. ISRN Psychiatry. 2012;2012:278730.

74. Sessoms J, Reid K, Williams I, Hinton I. Provider adherence to national guidelines for managing hypertension in African Americans. Int $J$ Hypertens. 2015;2015:498074.

75. Ardery G, Carter BL, Milchak JL, et al. Explicit and implicit evaluation of physician adherence to hypertension guidelines. J Clin Hypertens (Greenwich). 2007;9(2):113-119.
Patient Preference and Adherence

\section{Publish your work in this journal}

Patient Preference and Adherence is an international, peer-reviewed, open access journal that focuses on the growing importance of patient preference and adherence throughout the therapeutic continuum. Patient satisfaction, acceptability, quality of life, compliance, persistence and their role in developing new therapeutic modalities and compounds to optimize

\section{Dovepress}

clinical outcomes for existing disease states are major areas of interest for the journal. This journal has been accepted for indexing on PubMed Central. The manuscript management system is completely online and includes a very quick and fair peer-review system, which is all easy to use. Visit http://www. dovepress.com/testimonials.php to read real quotes from published authors. 